\title{
Gonadotrophin dose and timing of anaesthesia for laparoscopic artificial insemination in the puma (Felis concolor)
}

\author{
M. A. Barone $e^{1^{*}}$, D. E. Wildt ${ }^{1 \dagger}$, A. P. Byers ${ }^{1 \ddagger}$, M. E. Roelke $e^{2 \S}$, \\ C. M. Glass ${ }^{2}$ and J. G. Howard ${ }^{1}$ \\ ${ }^{\mathrm{I}}$ Department of Reproductive Physiology, National Zoological Park, Smithsonian Institution, Washington, \\ DC 20008, USA; and ${ }^{2}$ Florida Game and Fresh Water Fish Commission, Gainesville, FL 32601, USA
}

\begin{abstract}
Ovarian response to equine chorionic gonadotrophin (eCG) and human chorionic gonadotrophin (hCG), the effect of timing of anaesthesia relative to hCG injection and the use of laparoscopic intrauterine artificial insemination were examined in the puma (Felis concolor). In Expt 1, females were treated with $100(n=6)$ or $200(n=8)$ iu eCG (i.m.) followed 80 h later by 100 iu hCG (i.m.) and were then anaesthetized $40-43 \mathrm{~h}$ after hCG injection for ovarian assessment. Although there was no difference $(P>0.05)$ in the number of unovulated ovarian follicles, females treated with 200 iu eCG had more $(P<0.05)$ corpora lutea per female and more corpora lutea as a percentage of the total number of ovarian structures. In Expt 2, all females were treated with $200 \mathrm{iu}$ eCG and $80 \mathrm{~h}$ later with $100 \mathrm{iu} \mathrm{hCG}$, and then anaesthetized either $31-39 \mathrm{~h}$ (Group $\mathrm{A} ; n=8$ ) or $41-50 \mathrm{~h}$ (Group $\mathrm{B} ; n=6$ ) after hCG injection for ovarian assessment. All Group $B$ pumas ovulated compared with only three $(37.5 \%)$ Group A females $(P<0.05)$. Compared with Group A, Group B pumas had more corpora lutea per female, more corpora lutea as a percentage of the total number of ovarian structures, and fewer unovulated follicles $(P<0.05)$. One of nine post-ovulatory females laparoscopically inseminated in utero with $16 \times 10^{6}$ motile spermatozoa became pregnant and delivered a healthy cub. Administration of 200 iu eCG and 100 iu hCG followed by anaesthesia no earlier than $4 \mathrm{I} \mathrm{h}$ after hCG treatment is most likely to result in ovulation in pumas, and laparoscopic artificial insemination can be used to produce pregnancy in this species.
\end{abstract}

\section{Introduction}

Techniques such as artificial insemination (AI) and in vitro fertilization (IVF) hold great promise for maintaining the numbers and genetic diversity in endangered wildlife populations (Wildt, 1990; Wildt et al., 1992a, b). It is possible to induce ovulation in wild felids using exogenous gonadotrophins (Moore et al., 1981; Wildt et al., 1981; Dresser et al., 1982; Howard et al., 1992b; Donoghue et al., 1993). However, it is also apparent that there are unique species specificities that significantly influence the ultimate success of hormone treatment combined with assisted reproduction techniques for managing wildlife (Wildt $e t$ al., 1992a). The result is the need for more basic research directed towards individual highpriority species or populations.

The Florida panther (Felis concolor coryi) is the only panther subspecies free-living east of the Mississippi River (Anderson, 1983). As a result of habitat loss and other human-related

Present address: Association for Voluntary Surgical Contraception, 79 Madison Avenue, New York, NY 10016, USA.

${ }^{\dagger}$ Correspondence and reprint requests.

†Present address: Captive Breeding Specialist Group, Minnesota Zoo, 12101 Johnny Cake Ridge Road, Apple Valley, MN 55124-8199, USA.

\$resent address: Tanzania National Park, PO Box 3134, Arusha, Tanzania Received 26 July 1993. pressures, numbers of Florida panthers have declined to 30-50 individuals living in the southern Florida Big Cypress Swamp and Everglades ecosystems (United States Fish and Wildlife Service, 1987; Belden et al., 1988). Molecular genetic analyses, the large proportion of males exhibiting cryptorchidism, poor seminal quality and an increasing incidence of cardiac defects suggest that the Florida panther is experiencing severe inbreeding depression (Roelke et al., 1993; Barone et al., 1994).

One component of the 'Florida Panther Recovery Program' and a recommendation of a 'Population Viability Analysis Workshop' (Seal and Lacy, 1989) was that studies be implemented to (1) increase the fundamental database on puma reproductive physiology, and (2) develop supportive technologies, like AI, that could be useful for managing this small, fragile population. A foundation for this work was laid by Moore et al. (1981) and Bonney et al. (1981). Their investigations involving equine chorionic gonadotrophin (eCG) and human chorionic gonadotrophin (hCG) treatment and intrauterine insemination at laparotomy resulted in the first live wild felid birth following AI.

For the present studies, pumas of mixed or unknown genetic origin served as a model for the Florida panther. Specific experimental designs were based largely upon our earlier work, Downloaded from Bioscientifica.com at 04/26/2023 11:08:33AM 
which demonstrated that AI success in felids primarily depends upon the timing of anaesthesia and insemination relative to ovulation and the site of semen deposition (Howard et al., 1992a, b). There is also evidence in the domestic cat that fertilization or early embryonic development or both (hence, pregnancy outcome) may be negatively influenced by ovarian hyperstimulation following administration of exogenous gonadotrophins (Goodrowe ef al., 1988a, b; Howard et al., 1992a). This has been partly attributed to an excessive dose of eCG which has a long biological half-life in the circulation (Moor et al., 1984; Howard et al., 1992a).

It appears that optimal AI procedures for felids are those performed soon after ovulation involving intrauterine semen deposition and eCG and hCG dosages that produce minimal, if any, ovarian hyperstimulation (Howard et al., 1992a, b; Donoghue et al., 1993). The present studies on pumas were therefore designed to determine (1) the comparative efficacy of 100 versus 200 iu eCG for stimulating ovarian activity, (2) the timing of ovulation relative to hCG treatment, and (3) the use of laparoscopic intrauterine AI.

\section{Materials and Methods}

\section{Animals}

Studies were conducted at Octagon Wildlife Sanctuary (Punta Gorda, FL) and the Wild Animal Retirement Village (Waldo, FL) between November 1991 and April 1992. Fourteen female and nine male captive-born pumas of mixed or unknown genetic origin were used. Little information was available on the reproductive history or age of the individual animals, but some were known to have produced offspring. All were adults based on known captive history or subjective assessment of overall body size. Pumas were housed in outdoor enclosures with natural lighting, either singly or in groups of up to four animals of the same sex. Animals were fed a commercial carnivore diet (Nebraska Brand Feline Diet, North Platte, NE) or a combination of the commercial diet plus chicken with a feline vitamin and mineral supplement (Feline Spectrum, PRN Pharmacal Inc., Pensacola, FL). Water was available ad libitum.

\section{Exogenous gonadotrophin treatment}

Gonadotrophin doses and the time interval between injections were chosen on the basis of results of our prior work with the domestic cat (Donoghue et al., 1992b; Howard et al., 1992a). Females in Expt 1 were treated with either $100(n=6)$ or $200(n=8)$ iu eCG (i.m.; Equitech International Ltd Kerrville, TX) to stimulate ovarian follicular development. All females in Expt $2(n=14)$ received $200 \mathrm{iu}$ eCG. In both studies, females were injected with 100 iu hCG (i.m., Sigma Chemical Company, St Louis, MO) approximately $80 \mathrm{~h}( \pm 1 \mathrm{~h})$ after eCG treatment. Injections were delivered by syringe dart using a blow pipe or a commercial remote delivery system (Telinject Inc., Saugus, CA). Because of limited availability of animals, it was necessary to use the same females in Expt 1 and Expt 2. There were 21-22 weeks between the two experiments.

\section{Laparoscopic assessment of ovarian activity}

Animals were fasted for at least $12 \mathrm{~h}$ before laparoscopy. Females were anaesthetized at various times after hCG injection based on assigned treatment (see below). Anaesthesia was induced by an i.m. injection using Telazol (A. H. Robins Company, Richmond, VA; $2.7-11.4 \mathrm{mg} \mathrm{kg}^{-1}$ body mass) or a combination of Telazol $\left(6.6-14.2 \mathrm{mg} \mathrm{kg}^{-1}\right)$ and ketamine hydrochloride (Aveco Co Inc., Fort Dodge, IA; 3.8-6.5 mg $\mathrm{kg}^{-1}$ ) delivered by syringe dart. After stabilization and intubation, surgical anaesthesia was maintained using isofluraneoxygen inhalation anaesthesia.

In Expt 1, anaesthesia was induced approximately $40-43 \mathrm{~h}$ after hCG injection and animals were subjected to laparoscopy to assess ovarian activity. Females in Expt 2 were anaesthetized either 31-39 h (Group A, $n=8$ ) or 41-50 h (Group B, $n=6$ ) after hCG treatment, and laparoscopy was performed. Females in Expt 2 in which one or more corpora lutea were observed at the time of laparoscopy were inseminated (see below).

Laparoscopy was performed as described by Miller et al. (1990). Briefly, animals were placed on their backs and were tilted head down at an angle of approximately $45^{\circ}$ from vertical. A pneumoperitoneum was created with room air instilled through a Verres needle using a manual insufflator bulb (Richard Wolf Medical Instruments Corp., Rosemont, IL). A 7 or $10 \mathrm{~mm}$ diameter $180^{\circ}$ laparoscope (Richard Wolf Medical Instruments Corp.) was inserted along the midline $3-5 \mathrm{~cm}$ cranial to the umbilicus. All aspects of each ovary were examined for preovulatory follicles (>2 mm diameter) and corpora lutea, which were classified according to our previous criteria (Wildt and Seager, 1980; Wildt et al., 1981).

\section{Semen collection and processing}

Males were anaesthetized with Telazol (A. H. Robins Co.; $4.5-10.1 \mathrm{mg} \mathrm{kg}^{-1}$ body mass, i.m.) administered by dart syringe. Electroejaculates were collected and processed for AI according to previously described techniques (Howard et al., 1986 , 1992a, b). Briefly, an AC-60 Hz sine-wave electroejaculator and rectal probe were used to administer a regimented series of low voltage $(2-5 \mathrm{~V})$ stimuli. Semen was examined by phase contrast microscopy for a subjective assessment of percentage sperm motility and progressive sperm motility (on a scale of $0-5$ where $0=$ no movement and 5 = rapid forward progression; Howard et al., 1986). Aliquots were processed as previously described for determining the concentration of spermatozoa per millilitre of ejaculate and structural morphology (Howard et al., 1986).

Sperm samples exhibiting at least $50 \%$ motility and a 3.0 progressive motility score were diluted 1:I with Ham's F10 culture medium (Irvine Scientific, Santa Ana, CA) supplemented with $10 \%$ fetal calf serum (Irvine Scientific), centrifuged $(300 \mathrm{~g}$ for $10 \mathrm{~min}$ ) and the sperm pellet resuspended with $200 \mu \mathrm{l}$ of fresh culture medium. Processed samples were maintained at room temperature $\left(21^{\circ} \mathrm{C}\right)$ in darkness. Immediately before insemination, processed semen was assessed for percentage motility, progressive motility and concentration. Each uterine horn was inseminated with $100 \mu \mathrm{l}$ of sperm suspension (see below). Semen from five of the nine males was used for insemination. The number of motile spermatozoa inseminated 
Table 1. Ovarian activity in pumas treated with 100 or 200 iu equine chorionic gonadotrophin (eCG) followed $80 \mathrm{~h}$ later by 100 iu human chorionic gonadotrophin (hCG)

\begin{tabular}{|c|c|c|}
\hline Parameters & eCG $(100 \mathrm{iu})(n=6)$ & eCG $(200 \mathrm{iu})(n=8)$ \\
\hline Time of anaesthesia after $\mathrm{hCG}(\mathrm{h})^{\mathrm{a}}$ & $\begin{array}{l}42.3 \pm 0.6 \\
(41.3-45.0)\end{array}$ & $\begin{array}{l}40.5 \pm 1.0 \\
(37.3-44.8)\end{array}$ \\
\hline Number of unovulated follicles per female ${ }^{a}$ & $\begin{array}{l}3.0 \pm 1.1 \\
(0-7)\end{array}$ & $\begin{array}{c}3.1 \pm 1.1 \\
(0-7)\end{array}$ \\
\hline Number of corpora lutea/female ${ }^{a}$ & $\begin{array}{l}0.8 \pm 0.4^{b} \\
(0-2)\end{array}$ & $\begin{array}{l}3.5 \pm 1.0^{c} \\
(0-8)\end{array}$ \\
\hline Number of post-ovulatory females/total number of females $(\%)$ & $3 / 6 \quad(50.0 \%)$ & $6 / 8 \quad(75.0 \%)$ \\
\hline Total number of unovulated follicles/total number of ovarian structures $(\%)^{d}$ & $17 / 23(73.9 \%)$ & $25 / 53(47.2 \%)$ \\
\hline Total number of corpora lutea/total number of ovarian structures $(\%)^{\mathrm{d}}$ & $6 / 23(26.1 \%)^{b}$ & $28 / 53(52.8 \%)^{\mathrm{c}}$ \\
\hline
\end{tabular}

${ }^{a}$ Values are means $\pm \mathrm{SEM}$. Values in parentheses represent ranges.

b,c Within rows, values with different superscripts are significantly different $(P<0.05)$.

${ }^{\mathrm{d}}$ Total number of ovarian structures equals the total number of follicles ( $>2 \mathrm{~mm}$ in diameter) plus total number of corpora lutea.

depended upon the concentration of spermatozoa in the initial ejaculate. In three instances, where the concentration was low, semen from two males was mixed and used to inseminate a single female.

\section{Laparoscopic $A I$ and pregnancy diagnosis}

Females in Expt 2 determined to be post-ovulatory $(n=9)$ by the presence of at least one corpus luteum were artificially inseminated using a laparoscopic intrauterine procedure previously used in the domestic cat (Howard et al., 1992a), cheetah (Acinonyx jubatus; Howard et al., 1992b) and tiger (Panthera tigris altaicia; Donoghue et al., 1993). An accessory forceps (Richard Wolf Medical Instruments Corp.) was inserted 3-5 cm lateral to the umbilicus and used to elevate each uterine horn to the ventral body wall. The horn was cannulated with a 20 gauge feline indwelling catheter (Sovereign, Sherwood Medical, St Louis, $\mathrm{MO}$ ) inserted percutaneously into the proximal third of the lumen. The stylette was removed, polyethylene tubing ( $\mathrm{PE}$ 10; Intramedic, Clay Adams, Parsippany, NJ) containing processed semen was inserted through the catheter into the uterine lumen and the semen expelled. The insemination procedure was repeated on the contralateral horm. Time from anaesthesia induction to $\mathrm{AI}$ averaged $108 \mathrm{~min}$ (range 75-180 min). Females were anaesthetized 67-73 days after $\mathrm{AI}$ and radiographed for pregnancy status.

\section{Statistical analysis}

One-factor analysis of variance, followed by the Fisher least significant difference procedure, was used to test for significantly different effects of the mean time of anaesthesia after hCG injection, and for significant differences in the number of follicles and corpora lutea observed in the groups treated with 100 and 200 iu eCG (Expt 1). Similar procedures were carried out to determine differences between the number of follicles and corpora lutea in Group A females compared with Group B females in Expt 2. In both studies, the number of postovulatory females per total number of females, the total number of unovulated follicles per total number of ovarian structures, and the total number of corpora lutea per total number of ovarian structures between treatment groups were compared using $\chi^{2}$ analysis.

\section{Results}

\section{Experiment 1}

Time of anaesthesia induction relative to hCG injection was not different $(P>0.05)$ between gonadotrophin dosage groups (Table 1). Both 100 and 200 iu eCG stimulated comparable $(P>0.05)$ follicular development, but 200 iu produced four times more $(P<0.05)$ corpora lutea than did $100 \mathrm{iu}$ (Table 1$)$. There were no statistically significant differences $(P>0.05)$ in the proportion of females ovulating or the number of unovulated follicles as a percentage of the total number of ovarian structures between groups. However, compared with females treated with 100 iu eCG, pumas treated with 200 iu eCG had more corpora lutea $(P<0.05)$ as a percentage of the total number of ovarian structures (Table 1 ).

\section{Experiment 2}

There was no difference $(P>0.05)$ at laparoscopy in the number of follicles observed between females anaesthetized 31-39 h (Group A) and 41-50 h (Group B) after hCG treatment (Table 2). However, Group B females had three times more $(P<0.05)$ corpora lutea. All pumas in Group B ovulated compared with only $37.5 \%$ of those in Group A $(P<0.05)$. Group B females had fewer $(P<0.05)$ unovulated follicles and more $(P<0.05)$ corpora lutea as a percentage of the total number of ovarian structures compared with Group A animals (Table 2).

For the nine post-ovulatory pumas inseminated, the time of anaesthesia after hCG injection ranged from 33.5 to $50 \mathrm{~h}$, with six of the nine pumas being from Group B (41-50 h after hCG treatment). The ovarian response to the gonadotrophin Downloaded from Bioscientifica.com at 04/26/2023 11:08:33AM 
Table 2. Ovarian activity in pumas treated with $200 \mathrm{iu}$ equine chorionic gonadotrophin (eCG) and $100 \mathrm{iu}$ human chorionic gonadotrophin (hCG), and anaesthetized $31-39$ or $41-50 \mathrm{~h}$ after hCG injection

\begin{tabular}{|c|c|c|}
\hline \multirow[b]{2}{*}{ Parameters } & \multicolumn{2}{|c|}{ Time of anaesthesia after hCG injection } \\
\hline & $3 I-39$ h (Group A) $(n=8)$ & $41-50 \mathrm{~h}($ Group B) $(n=6)$ \\
\hline Number of unovulated follicles per female ${ }^{a}$ & $\begin{array}{c}3.6 \pm 0.8 \\
(0-6)\end{array}$ & $\begin{array}{c}1.8 \pm 1.2 \\
(0-7)\end{array}$ \\
\hline Number of corpora lutea per female ${ }^{a}$ & $\begin{array}{c}1.3 \pm 0.68^{b} \\
(0-5)\end{array}$ & $\begin{array}{c}4.2 \pm 1.0^{c} \\
(0-8)\end{array}$ \\
\hline Number of post-ovulatory females/total number of females (\%) & $3 / 8 \quad(37.5 \%)^{b}$ & $6 / 6 \quad(100.0 \%)^{\mathrm{c}}$ \\
\hline Total number of unovulated follicles/total number of ovarian structures $(\%)^{d}$ & $29 / 39(74.4 \%)^{b}$ & $11 / 36 \quad(30.6 \%)^{c}$ \\
\hline Total number of corpora lutea/total number of ovarian structures $(\%)^{\mathrm{d}}$ & $10 / 39(25.6 \%)^{\mathrm{b}}$ & $25 / 36 \quad(69.4 \%)^{\mathrm{c}}$ \\
\hline
\end{tabular}

${ }^{2}$ Values are means $\pm S E M$. Values in parentheses represent ranges.

${ }^{b, c}$ Within rows, values with different superscripts are significantly different $(P<0.05)$.

${ }^{\mathrm{d}}$ Total number of ovarian structures equals the total number of follicles ( $>2 \mathrm{~mm}$ in diameter) plus total number of corpora lutea.

Table 3. Ovarian activity and inseminate traits at the time of artificial insemination (AI) of post-ovulatory pumas inseminated laparoscopically

\begin{tabular}{|c|c|c|c|c|c|c|c|c|}
\hline Female number & $\begin{array}{l}\text { Interval from } \\
\text { hCG to } A I(h)\end{array}$ & $\begin{array}{l}\text { Number of } \\
\text { unovulated } \\
\text { follicles }\end{array}$ & $\begin{array}{l}\text { Number of } \\
\text { corpora lutea }\end{array}$ & $\begin{array}{l}\text { Sperm } \\
\text { motility } \\
(\%)\end{array}$ & $\begin{array}{c}\text { Sperm } \\
\text { progressive } \\
\text { motility }^{\mathrm{a}}\end{array}$ & $\begin{array}{c}\text { Morphologically } \\
\text { normal } \\
\text { spermatozoa } \\
(\%)\end{array}$ & $\begin{array}{c}\text { Motile } \\
\text { sperm inseminated } \\
\left(\times 10^{6}\right)\end{array}$ & Pregnancy \\
\hline 1 & 44.8 & 0 & 8 & 50 & 3.0 & 4 & 5.6 & - \\
\hline 2 & 41.0 & 0 & 4 & 75 & 3.0 & 11 & 16.0 & + \\
\hline 3 & 39.0 & 6 & 3 & 50 & 3.5 & 1 & 42.8 & - \\
\hline 4 & 38.0 & 6 & 5 & 70 & 4.5 & 26 & 12.0 & - \\
\hline 5 & 42.5 & 0 & 5 & 50 & 4.0 & 8 & 5.5 & - \\
\hline 6 & 43.5 & 7 & 3 & 35 & 3.0 & 4 & 25.0 & - \\
\hline 7 & 33.5 & 1 & 2 & 65 & 4.0 & 25.5 & 39.0 & - \\
\hline 8 & 46.3 & 0 & 4 & 55 & 4.0 & 12 & 44.0 & - \\
\hline 9 & 50.0 & 4 & 1 & 75 & 4.5 & 11.5 & 49.4 & - \\
\hline Mean $( \pm$ SEM $)$ & $42.0 \pm 1.6$ & $2.7 \pm 1.0$ & $3.9 \pm 0.7$ & $58.3 \pm 4.6$ & $3.7 \pm 0.2$ & $11.4 \pm 9.0$ & $26.6 \pm 5.9$ & \\
\hline
\end{tabular}

hCG: human chorionic gonadotrophin.

${ }^{\mathrm{a}} \mathrm{O}=$ no movement; $5=$ rapid forward progression.

treatment was highly variable among individuals (Table 3 ). Sperm donor seminal traits were similar to those measured in our laboratory in earlier puma studies (Wildt et al., 1988; Barone $e t$ al., 1994). Immediately after electroejaculation, mean ( \pm SEM) ejaculate volume $(\mathrm{ml})$, percentage sperm motility, sperm progressive motility score and sperm concentration $\mathrm{ml}^{-1}$ of ejaculate $\left(\times 10^{6}\right)$ were $3.3 \pm 0.6,65.5 \pm 2.9,3.6 \pm 0.2$ and $37.9 \pm 10.4$, respectively. Although variable, most males ejaculated low numbers of morphologically normal spermatozoa $(\leq 26 \%$, Table 3$)$. Overall, sperm pleiomorphisms included macrocephaly $(0.1 \%)$, microcephaly $(0.9 \%)$ and bicephaly $(0.2 \%)$, abnormal acrosome $(9.7 \%)$, midpiece aplasia $(3.1 \%)$, coiled flagellum (20.7\%), bent midpiece $(23.7 \%)$, bent flagellum $(13.3 \%)$, proximal cytoplasmic droplet $(13.0 \%)$, distal cytoplasmic droplet $(1.9 \%)$, and spermatids $(2.0 \%)$.

Female 2, which had been anaesthetized $41 \mathrm{~h}$ after hCG injection (Group B), was diagnosed as pregnant by radio- graphic examination on day 69 after AI. She delivered a single, healthy male cub following a gestation of 92 days.

\section{Discussion}

These studies demonstrate that a low dose of eCG and hCG induces follicular development and ovulation in pumas, and that viable offspring can be produced by laparoscopic intrauterine $\mathrm{AI}$ after this hormonal treatment. Although both 100 and $200 \mathrm{iu}$ eCG induced follicular activity, the higher dose caused a greater proportion of follicles to ovulate and more corpora lutea to form per female.

One of our goals was to determine the lowest eCG dose that would cause sufficient follicular development yet minimize ovarian hyperstimulation, thus resulting in the least disruption to the endogenous hormonal milieu. The negative impact of exogenous gonadotrophins on fertilization, embryo quality and Downloaded from Bioscientifica.com at 04/26/2023 11:08:33AM 
implantation has been demonstrated in an array of species. For example, mice treated with eCG and hCG have lower implantation rates following embryo transfer than do spontaneously oestrous recipients (Fossum et al., 1989). Low pregnancy success after gonadotrophin treatment, IVF and embryo transfer in women is commonly considered to be partly related to abnormal endocrine profiles (DeCherney et al., 1985; Stanger and Yovich, 1985; Gifley-Baird et al., 1986). High peripheral oestradiol concentrations, a byproduct of ovarian hyperstimulation, lead to altered endometrial receptivity, impaired implantation and increased early embryonic death (Pittaway and Wents, 1983; Diamond et al., 1984; Gifley-Baird et al., 1986).

Domestic cats treated with oestrogen on the day after coitus have retarded ovum transport and more degenerate ova than do untreated counterparts (Herron and Sis, 1974). Goodrowe et al. (1988a) reported that FSH-treated cats have altered hormonal profiles and produce more poor-quality embryos and unfertilized oocytes than do naturally oestrous females. In another study, approximately $40 \%$ of embryos recovered from eCG-treated, laparoscopically inseminated cats were retarded in development or of poor quality (Howard et al., 1992a).

There is evidence that domestic cats treated with exogenous gonadotrophins experience a secondary wave of ovarian follicular development. In eCG-treated females, the number of corpora lutea I week after follicular aspiration (for oocyte recovery for IVF) is significantly greater than the number of follicles originally identified and aspirated (Goodrowe ef al., 1988 b). In contrast, the number of corpora lutea in naturally oestrous controls 1 week after mating is similar to the number of follicles noted at a premating laparoscopy. eCG-treated domestic cats also express abnormal circulating oestrogen and progesterone profiles compared with naturally oestrous females (Goodrowe et al., 1988b).

In addition, Howard et al. (1992a) noted a large increase in the number of corpora lutea in domestic cats on day 6 after AI compared with the number observed on the day laparoscopic AI took place (day 0), suggesting that 'accessory' follicles had formed and ovulated and/or luteinized. This phenomenon has also been documented in tigers treated with eCG and hCG: $48 \mathrm{~h}$ after aspirating ovarian follicles, large numbers of unovulated follicles and a high concentration of circulating oestradiol are observed (Donoghue et al., 1990). It seems likely that the altered hormonal profiles (Goodrowe et al., 1988a, b; Donoghue et al., 1990) are a direct result of residual exogenous gonadotrophin, causing 'accessory' follicle recruitment, the overall effect being a less than optimal environment for fertilization or preimplantation embryo development.

Earlier reports of administration of eCG and hCG to pumas relied upon doses at least ten times higher than those used here, and there is some evidence that ovarian hyperstimulation occurred (Bonney et al., 1981; Miller et al., 1990). Bonney et al. (1981) noted pronounced follicular development and a marked rise in the concentration of circulating oestradiol in eCGtreated pumas compared with untreated, naturally oestrous controls. In one study (Miller et al., 1990), the number of ovarian follicles per female ranged from 8 to 52 (mean $=27$ ), indicating significant hyperstimulation in some individuals.

There appears to be remarkable species-specific sensitivity to eCG among the felids. The eCG dosage required is not dependent on body mass. For example, $100 \mathrm{iu}$ eCG is used routinely to elicit follicular development in the domestic cat for laparoscopic AI (Howard et al., 1992a). A recent study indicated that 200 iu eCG is optimal for the cheetah (Howard et al., 1993a), a finding that is consistent with the response of the puma in the present study. However, these two species weigh approximately $7-8$ times that of the domestic cat, yet require an eCG dose only twice as great to stimulate comparable ovarian activity. Similarly, the clouded leopard (Neofelis nebulosa), a species weighing 4-5 times the domestic cat, requires only 50-100 iu eCG to induce sufficient follicular growth to allow ovulation (Howard et al., 1993a).

Howard et al. (1992a) first demonstrated that AI success in felids is related to the timing of anaesthesia relative to ovulation. When anaesthesia is induced with ketamine $\mathrm{HCl}$, maintained with isoflurane-oxygen inhalation anaesthesia, and laparoscopy performed before ovulation, pregnancy rates are approximately $14 \%$ compared with $50 \%$ if these procedures are conducted after ovulation. This specific anaesthetic regimen interferes with ovulation in the cat. Although AI success obviously depends on the absolute need for ovulation, onset of follicular rupture relative to hCG administration must also be known for the procedure to be successful. The domestic cat ovulates 25-30 h after hCG administration (Hamner et al., 1970; Sojka et al., 1970; Howard et al., 1992a). Less precise information is available for most wild felids, although gonadotrophin-treated cheetahs (Wildt et al., 1981; Donoghue et al., 1992a), pumas (Miller et al., 1990) and tigers (Donoghue ef al., 1990) can begin to ovulate as early as $24-26 \mathrm{~h}$ after hCG injection. However, most ovulations probably occur later. For example, Bonney et al. (1981) noted that ovulation in a single puma occurred on two occasions $24-40 \mathrm{~h}$ after hCG administration. We recently reported that none of three hCG-treated cheetahs had ovulated by 37-39 h, but seven of seven had ovulated by $42.5-47 \mathrm{~h}$ following hCG injection (Howard et al., 1992a). The present results indicate that ovulation in pumas was more likely to have occurred $41 \mathrm{~h}$ after hCG injection than before. This time interval was consistent with that noted in the cheetah (Howard et al., 1992a) and clouded leopard (J. G. Howard and D. E. Wildt, unpublished), but was $10-15$ h later than the interval documented in the domestic cat.

One of nine inseminated females became pregnant and produced a live cub. The relatively low AI success rate may have been partly related to altered endocrine profiles caused by suboptimal gonadotrophin treatment. However, the relatively poor quality of the inseminate, especially the high numbers of structurally abnormal spermatozoa (mean, 88.6\%), may also have played a role. Efficiency of gamete interaction in felids is inversely related to the degree of teratospermia. Spermatozoa from normospermic domestic cats are more likely to bind and penetrate domestic cat zonae pellucidae and cause embryo cleavage in vitro than that from teratospermic males (Howard et al., 1991, 1993b). It may therefore be difficult to achieve high pregnancy rates using assisted reproduction in species such as the puma that tend to produce extraordinarily high proportions of pleiomorphic spermatozoa. Nonetheless, we are encouraged by these early results and continue to study the puma as a model for the endangered Florida panther and other rare felid species.

Downloaded from Bioscientifica.com at 04/26/2023 11:08:33AM 
The authors thank Octagon Wildlife Sanctuary and the Wild Animal Retirement Village for providing animal access and assistance, M. Lamm, N. Keeling, J. Schumacher, V. Gibaldi, K. Cooper, B. Jennette, J. Brown, R. Davis, L. Herbst, J. L. Gingerich, K. Winter J. Maupin, G. Schutler, and also J. Buff for assistance with data preparation and analysis. They are especially indebted to P. Caron for his dedication, assistance and generous hospitality, which made these studies possible. Funding was provided by federal grant-in-aid funds administered through the US Fish and Wildlife Service under section 6 of the Endangered Species Act, the National Zoo's NOAHS Center, the Friends of the National Zoo, the Florida Panther Research and Management Trust Fund, Florida nongame trust funds, and the Ralston Purina Big Cat Survival Fund administered through the American Association of Zoos Parks and Aquariums.

\section{References}

Anderson AE (1983) A critical review of literature on the puma (Felis concolor) Special Report Number 54, Colorado Division of Wildlife, Colorado State Publication

Barone MA, Roelke ME, Howard JG, Brown JL, Anderson AE and Wildt DE (1994) Reproductive characteristics of male Florida panthers: comparative studies from Florida, Colorado, Latin America and North American zoos Journal of Mammalogy 75 150-162

Belden RC, Frankenberger WB, McBride RT and Schwilert ST (1988) Panther habitat use in southern Florida Journal of Wildlife Management 52 660-663

Bonney RC, Moore HDM and Jones DM (1981) Plasma concentrations of oestradiol- $17 \beta$ and progesterone, and laparoscopic observations of the ovary in the puma (Felis concolor) during oestrus, pseudopregnancy and pregnancy Journal of Reproduction and Fertility $63523-531$

DeCherney AH, Tarlatzis BC and Laufer N (1985) Follicular development: lessons learned from human in vitro fertilization American Journal of Obstetrics and Gynecology 153 911-923

Diamond MP, Wentz AC, Herbert CM, Pittaway DE, Maxson WS and Daniel JF (1984) One ovary or two: difference in ovulation induction, estradiol levels and follicular development in a program for in vitro fertilization Fertility and Sterility 41 524-529

Donoghue AM, Johnson LA, Seal US, Armstrong DL, Tilson RL, Wolf P, Petrini K, Simmons LG, Gross T and Wildt DE (1990) In vitro fertilization and embryo development in vitro and in vivo in the tiger (Panthera tigris) Biology of Reproduction $43733-747$

Donoghue AM, Howard JG, Byers AP, Goodrowe KL, Bush M, Blumer E, Lukas J, Stover J, Snodgrass K and Wildt DE (1992a) Correlation of sperm viability with gamete interaction and fertilization in vitro in the cheetah (Acinonyx jubatus) Biology of Reproduction 46 1047-1056

Donoghue AM, Johnson LA, Munson L, Brown JL and Wildt DE (1992b) Influence of gonadotropin treatment interval on follicular maturation, in vitro fertilization, circulating steroid concentrations, and subsequent luteal function in the domestic cat Biology of Reproduction 46 972-980

Donoghue AM, Johnson LA, Armstrong DL, Simmons LG and Wildt DE (1993) Birth of a Siberian tiger cub (Panthera tigris altaicia) following laparoscopic intrauterine artificial insemination Joumal of Zoo and Wildlife Medicine 24 185-189

Dresser BL, Kramer L, Reece B and Russel PT (1982) Induction of ovulation and successful artificial insemination in a Persian leopard (Panthera pardus saxicolor) Zoo Biology 1 55-57

Fossum GT, Davidson A and Paulson R (1989) Ovarian hyperstimulation inhibits embryo implantation in the mouse Journal of In Vitro Fertilization and Embryo Transfer 6 7-10

Gifley-Baird AA, O'Neil C, Sinosich MF, Porter RN, Pike IL and Saunders DM (1986) Failure of implantation in human in vitro fertilization and embryo transfer patients: the effects of altered progesterone-estrogen ratios in humans and mice Fertility and Sterility 45 69-74

Goodrowe KL, Howard JG and Wildt DE (1988a) Comparison of embryo recovery, embryo quality, oestradiol- $17 \beta$ and progesterone profiles in domestic cats (Felis catus) at natural or induced oestrus Journal of Reproduction and Fertility 82 553-561

Goodrowe KL, Wall RL, O'Brien SJ, Schmidt PM and Wildt DE (1988b) Developmental competence of domestic cat follicular oocytes after fertilization in vitro Biology of Reproduction 39 355-372
Hamner CE, Jennings J and Sojka NJ (1970) Cat (Felis catus) spermatozoa require capacitation Journal of Reproduction and Fertility 23 477-480

Herron MA and Sis RF (1974) Ovum transport in the cat and the effect of estrogen administration American Journal of Veterinary Research 35 $1277-1279$

Howard JG, Bush M and Wildt DE (1986) Semen collection, analysis and cryopreservation in nondomestic mammals. In Current Therapy in Theriogenology, pp 1047-1053 Ed. DA Morrow. WB Saunders, Philadelphia

Howard JG, Bush M and Wildt DE (1991) Teratospermia in domestic cats compromises penetration of zona-free hamster ova and cat zonae pellucidae Journal of Andrology 12 36-45

Howard JG, Barone MA, Donoghue AM and Wildt DE (1992a) The effect of pre-ovulatory anaesthesia on ovulation in laparoscopically inseminated domestic cats Journal of Reproduction and Fertility 96 175-186

Howard JG, Donoghue AM, Barone MA, Goodrowe KL, Blumer E, Snodgrass K, Starnes D, Tucker M, Bush M and Wildt DE (1992b) Successful induction of ovarian activity and laparoscopic intrauterine artificial insemination in the cheetah (Acinonyx jubatus) Journal of Zoo and Wildlife Medicine 23 288-300

Howard JG, Barone MA, Byers AP, Roth TR and Wildt DE (1993a) Ovulation induction sensitivity and laparoscopic intrauterine insemination in the cheetah, puma and clouded leopard Journal of Andrology (Jan/Feb Supplement) p 55 (Abstr.)

Howard JG, Donoghue AM, Johnston LA and Wildt DE (1993b) Zona pellucida filtration of structurally abnormal spermatozoa and reduced fertilization in teratospermic cats Biology of Reproduction 49 131-139

Miller AM, Roelke ME, Goodrowe KL, Howard JG and Wildt DE (1990) Oocyte recovery, maturation and fertilization in vitro in the puma (Felis concolor) Journal of Reproduction and Fertility 88 249-258

Moor RM, Kruip ThAM and Green D (1984) Intraovarian control of folliculogenesis: limits to superovulation? Theriogenology 21 103-116

Moore HDM, Bonney RC and Jones DM (1981) Successful induced ovulation and artificial insemination in the puma (Felis concolor) Veterinary Record 108 282-283

Pittaway DE and Wents SC (1983) Evaluation of the exponential rise of serum estradiol concentrations in human menopausal gonadotropin induced cycles Fertility and Sterility 40 763-767

Roelke ME, Martenson JS and O'Brien SJ (1993) The consequences of demographic reduction and genetic depletion in the endangered Florida panther Current Biology 3 340-350

Seal US and Lacy RC (1989) Florida Panther (Felis concolor coryi) Viability Analysis and Species Survival Plan United States Fish and Wildlife Service Cooperative Agreement no 14-16-004-90-902

Sojka NJ, Jennings LL and Hamner CE (1970) Artificial insemination in the cat (Felis catus) Laboratory Animal Care 20 198-204

Stanger JD and Yovich JL (1985) Reduced in vitro fertilization of human oocytes from patients with raised basal luteinizing hormone levels during the follicular phase British Journal of Obstetrics and Gynaecology 92 385-390

United States Fish and Wildlife Service (1987) Florida Panther Recovery Plan Florida Panther Interagency Committee, Atlanta, Georgia

Wildt DE (1990) Potential applications of IVF technology for species conservation. In Fertilization in Mammals, pp 349-364 Eds BD Bavister, J Cummins and ERS Roldan. Serono Symposium USA, Norwell, MA

Wildt DE and Seager SWJ (1980) Ovarian and uterine morphology during various stages of the domestic cat reproductive cycle as determined by laparoscopy. In Current Therapy in Theriogenology, pp 828-832 Ed. DA Morrow. WB Saunders, Philadelphia

Wildt DE, Platz CP, Seager SWJ and Bush M (1981) Induction of ovarian activity in the cheetah (Acinonyx jubatus) Biology of Reproduction 24 217-222

Wildt DE, Phillips LG, Simmons LG, Chakraborty PK, Brown JL, Howard JG, Teare A and Bush $M$ (1988) A comparative analysis of ejaculate and hormonal characteristics of the captive male cheetah, tiger, leopard and puma Biology of Reproduction 38 245-255

Wildt DE, Donoghue AM, Johnston LA, Schmidt PM and Howard JG (1992a) Species and genetic effects on the utility of biotechnology for conservation. In Biotechnology and the Conservation of Genetic Diversity, pp 45-61 Eds HDM Moore, WV Holt and GM Mace. Clarendon Press, Oxford

Wildt DE, Monfort SL, Donoghue AM, Johnson LA and Howard JG (1992b) Embryogenesis in conservation biology - or, how to make an endangered species embryo Theriogenology 37 161-184 